\title{
Borders moderating distance: A Social Network Analysis of Spatial Effects on Policy Interaction
}

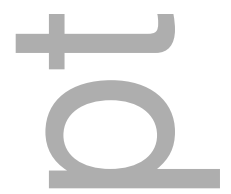

Christophe Sohn ${ }^{1}$

Department of Urban Development and Mobility, Luxembourg Institute of Socio-Economic Research (LISER), 11 Portes des Sciences, L-4366 Esch-sur-Alzette, Luxembourg

Dimitris Christopoulos

Department of Public Governance and Management, MODUL University Vienna, Am Kahlenberg 1, 1190 Vienna, Austria

\section{Johan Koskinen}

Melbourne School of Psychological Sciences, Faculty of Medicine, Dentistry, and Health Sciences, The University of Melbourne, Victoria 3010 Australia

\section{Acknowledgements}

This research is part of the MetroNet project supported by the National Research Fund of Luxembourg (FNR Project C09/SR/03).

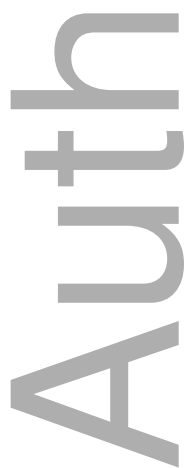

\footnotetext{
${ }^{1}$ Corresponding author. Tel.: +352 585855 613. E-mail address: christophe.sohn@liser.lu. This is the author manuscript accepted for publication and has undergone full peer review but has not been through the copyediting, typesetting, pagination and proofreading process, which may lead to differences between this version and the Version of Record. Please cite this article as doi: $10.1111 /$ GEAN.12218
}

This article is protected by copyright. All rights reserved 
DR. CHRISTOPHE SOHN (Orcid ID : 0000-0002-2448-288X)

\begin{abstract}
Article type : Original Article
Borders moderating distance: A Social Network Analysis of Spatial Effects on Policy Interaction
\end{abstract}

\title{
Introduction
}

The analysis of spatial interaction has long been a privileged field of investigation for geography and regional science and covers a wide range of human processes and analytical approaches (Fotheringham and O'Kelly 1989). Since the introduction of quantitative methods in the 1960s, network analysis has been primarily applied to transportation geography and for the analysis of infrastructural or physical networks (Hagget and Chorley 1969). For a long time, the exchanges between geographers, regional scientists and social network analysts thus remained limited (Grabher 2006). From the 1990s on, recognition of the crucial role of knowledge flows in the capacity for learning and innovation, and more broadly, the economic performance of organizations and regions has sparked a growing interest in social networks. Insofar as the creation and transfer of knowledge does not only take place in a geographical context but also within a relational network of actors (individuals or organizations), analysis of the social and inter-organizational networks and the processes that govern their formation becomes crucial (Glückler, Lazega, and Hammer 2017). Over the last decade, the integration of social network analysis (SNA) into economic geography and regional science has brought to light new research questions, theoretical perspectives and analytical approaches (e.g., Autant-Bernard and Hazir 2013; Brueckner and Smirnov 2007; Ter Wal and Boschma 2009). In our eyes, this growing interest of geographers and social network analysts for a better combination of geographical and relational perspectives appears promising and justifies further investigations. 
As our contribution to the body of knowledge in this regard, the present paper integrates geographical effects beyond mere distance into the analysis of social networks. Our main contention is that in addition to spatial proximity, the presence of boundaries (national borders but also regional borders), which delineate, separate and differentiate space into distinct territorial units and jurisdictions influence the way in which relations occur (Radil, Flint, and Tita 2010). In an examination of multiple spatial effects the issue arises of how the different exogenous contextual factors may alter and confound the effects on one another (Adams, Faust, and Lovasi 2012). Additionally, spatial effects may be confounded by endogenous network processes, giving rise to tie dependencies (Koskinen and Lomi 2013). To address these methodological concerns, we rely on Exponential Random Graph Models (ERGM). These models are increasingly successful in a wide range of disciplines from the bio-sciences to sociology and political science. In geography, their use is still limited with the exception of a few studies in economic geography (see notably Broeckel and Hartog 2013). This lack of acquaintance with ERGM among geographers may be explained by the objective of this type of models, which aims above all to predict the formation of a link within a social network conditional on other influences, including geography. In such a perspective, geographical space is often considered as a function of linear distance and may be seen to be somewhat at odds with the perspectives favored by geographers (Glückler et al. 2017). Yet, as argued by Broekel et al. (2014), ERGM are capable of taking into account barrier effects on interaction other than just distance. We also believe that this class of models offers the possibility to tackle less trivial issues from a geographical point of view, hence our call to reassess their relevance for geographers.

Specifically, we show in a first step how the effect of distance on the exchange of information is less obvious than it seems at first sight, when we control for endogenous network effects and exogenous contextual factors with which it tends to be confounded. Beyond the various ways in which spatial configurations affect network relations, it is also the way in which they influence one another that gets our attention. Therefore, in a second step, we explore contextual moderating effects between distance and territorial borders by conditioning on spatially defined subsamples. By making use of simulated predictive data derived from the fitted ERGM, we investigate the marginal distribution of tie-probability as a function of distance for both domestic and cross-border relations, net of endogenous effects. Contrary to what could be 
expected, namely a cumulative effect between the friction of distance and the border barrier effect, we observe distance-related effects that diverge according to the territorial context. Thus, while the probability of interaction decreases with distance in the context of exchanges between actors belonging to the same territory, distance does not exert the same friction when it comes to cross-border interactions.

In order to grasp empirically how spatial distance and territorial borders influence interorganizational information exchange, we rely on original fieldwork and data that was collected from organizations involved in cross-border transportation governance within the cross-border regions of Lille (France/Belgium) and Basel (Switzerland/France/Germany). In these two European cross-border regions, the relative openness of national borders has allowed the free movement of goods, persons, services and capital and the implementation of various policies that aim to foster cross-border interactions and cooperation. Yet, the presence of more porous borders does not necessarily imply the disappearance of border effects linked to the persistence of institutional, cultural or mental barriers, hence the relevance of these cases to our study.

The analysis starts out by discussing the effects of distance and borders on social interactions and, in particular, inter-organizational information exchange. In a second step, the relevance of ERGM for combining network analysis and geographical analysis is introduced. The third section presents the choice of the two case studies and their main characteristics. The next section is dedicated to presenting the data and methods used. The identification of the actors interviewed, the description of the variables (dependent and independent) and the analytical strategy are successively addressed. The presentation of the results is structured in two parts. We first consider the different spatial effects on the formation of public transportation policy networks. We then focus on the moderating effect of borders on the spatial distance of ties. The last section concludes with insights gained.

\section{Theoretical considerations: the effects of spatial factors on social networks}

In geography, the notion of friction of distance is a truism. The idea expressed by Tobler (1970) that "everything is related to everything else, but near things are more related than distant things" has even been called the First Law of Geography. Among the disciplines that focus specifically on social relations, the influence of spatial proximity on the probability of engaging in social interaction has also long been acknowledged. Festinger, Schachter and Back (1950) were notably 
the first to empirically highlight the propinquity effect (i.e., people located close to each other have a higher probability of forming relationships). Such an effect has been empirically tested in various networks and contexts such as friendship ties (Preciado et al. 2012), neighborhood networks (Hipp and Perrin 2009) or the diffusion of political information (Baybeck and Huckfeldt 2002). The impact of distance on contacts and exchanges has also been acknowledged not only for individuals, but also for other types of social actors such as organizations (Lomi and Pallotti 2012). In these network studies, different scales have been considered, ranging from intra-organizational networks (Sailer and McCulloh 2012) to Internet users worldwide (Mok et al. 2010).

In the context of the present research which deals with information exchange within the context of European cross-border regions, this question of the effect of distance remains interesting for the following reasons. First, the effect of spatial proximity can be confounded with other dimensions of closeness such as cognitive, social or institutional proximity (Boschma 2005). Daraganova et al. (2012) also noted that the effect of distance can confound endogenous network effects. It is this aspect in particular that is of interest here. To evaluate the net effect of geographical distance, it is therefore necessary to control network effects such as triadic closure (Cassi and Plunket 2013). In the kind of inter-organizational networks where information and knowledge are exchanged, what remains of the friction of distance, once other effects that explain the exchange of information have been taken into account?

The second spatial effect we are interested in concerns the role of territorial borders. The analysis of border effects raises an interesting albeit under-scrutinized theoretical problem. Generally, there is a wide acceptance that borders have a disruptive influence on spatial interactions and communications (see notably Nijkamp, Rietveld, and Salomon 1990; Vinciguerra, Frenken, and Valente 2010). As territorial dividing lines, national borders frame social action and interaction. There is a greater ease of operating within known structures and networks and nation-states are the principal providers of such familiarity (Helliwell 1998). Furthermore, the existence of institutional, cultural or mental barriers - either inherited from past territorial constructions or actively reproduced - leads to increasing uncertainty and transactions costs and contributes to explaining why, even in contexts where cross-border integration appears to be strong, national borders still matter (Rietveld 2012). 
Yet, in the context of European integration where national borders (specifically intra-EU borders) have been progressively opened to the flows of people, goods, finance and services, the question of the role of border is less obvious than it seems. Hence, some authors have suggested that, in an integration context, borders could offer opportunities for actors and territories located in their vicinity rather than block exchanges and links (Van Geehuizen and Ratti 2001). The main reason why the opening of borders may offer new opportunities has to do with the possibility of taking advantage of their role as a contact zone (and not just as a barrier). Hence the border opportunity may therefore be founded on valorising mutual differences (i.e., complementarities) and processes of adaptation as well as mutual learning negotiated through frequent contacts (Sohn 2014). Engaging in cross-border collaborative relationships may also lead to fostering the human or financial capacities of organizations (resource pooling) or the sharing of costs (economies of scale). Finally, the symbolic dimension of the border can also be mobilized by actors that engage in cross-border activities and who aim to reinforce their political or institutional prestige and recognition. A recent study of the effect of borders on urban performance in Europe has shown that borders do exert ambivalent effects, some aspects being negative and others positive (Sohn and Licheron 2017). Yet, empirical analyses of the effects of territorial boundaries on social interactions are too rare and related to specific contexts. It is therefore difficult to prejudge the effects of borders on the exchange of information between organizations within the two European cross-border regions selected in this study.

Finally, the simultaneous consideration in the analysis of different factors raises the question of the impact of interaction effects and in particular the moderation effect that a variable is likely to have on the relationship between two other variables. A number of studies have highlighted the moderating effect of space on the impact of networks on firms' innovation (for an overview see Glückler 2013). The contingent nature of geographical proximity was emphasized, particularly in the bio-technology sector, where the effect of firms' centrality on innovation is linked to their relative proximity (Whittington et al. 2009). Interaction effects have also been highlighted in the other direction. In this case, the type of relationship between actors moderates the effect of space on the transmission of information and the dissemination of knowledge. Different works have shown that depending on the type of relationship considered (interpersonal or inter-organizational), the effect of geographical distance could vary. In some cases, information flows are facilitated between friends when they are geographically distant from one 
another (Bell and Zaheer 2007). In other words, certain network configurations make social interactions insensitive to the friction of distance; sometimes, it is even the long-distance interactions that are privileged.

What interests us in this paper is the extent to which territorial borders moderate how distance affects the exchanges of information among organizations. Based on how barrier effects are conceived in spatial interaction models, we expect that distance-decay is stronger for crossborder ties than it is for domestic ties. We would therefore have a cumulative process between two negative effects; in other words, crossing a border is equivalent to an additional distance as evidenced in international economics (see Engel and Rogers 1996). However, and based on how open borders may have positive effects on certain interactions, it is also conceivable that some actors have an interest in becoming more involved in cross-border relationships. In such a case, geographical distance would not constitute a hindrance to information exchange.

\section{Analytical method: Exponential Random Graph Models}

One of the fundamental features of networked structures is the conditional dependence of observations, especially between dyads with common actors. This intrinsic dependence among network ties thus violates the principle of independence of observations which is at the basis of inferential statistics. But more than just statistically correcting the effects of these dependencies, the main challenge is to consider the structural effects of networks in the modeling of social interactions. The approach to spatial interactions, which relies heavily on gravity models, has some limitations in satisfying the requirements of using network data (Broekel et al. 2014). Though strategies have been developed to take account of structural dependencies in gravity models (see notably Anderson and Wincoop 2003; Lesage and Pace 2008; Burger, Van Oort and Linders 2009), their possibilities remain limited and other modeling approaches seem more appropriate (Broekel et al. 2014).

Exponential random graph models are a class of statistical models for social networks (sometimes called $\mathrm{p}^{*}$ models) that allow researchers to model the structure of a network and infer the underlying processes that contribute to its formation (Lusher, Koskinen and Robins 2013). Over the last decade, they have become recognized as one of the central approaches in analyzing social networks (ibid.). Exponential random graph models provide a framework for integrating different network theories and statistically testing the derived hypotheses. Contrary to 
other models applied in SNA (e.g., binary logit models, quadratic assignment procedure models) that can take into account factors at the dyadic level only, ERGM can simultaneously incorporate three main categories of tie formation processes: network self-organization such as activity/popularity, reciprocity or closure, actor attributes such as age, gender, expertise or profession and exogenous contextual factors such as other networks and spatial factors (Lusher and Robins 2013).

When seeking to infer the effect of space, ERGM offer a great flexibility and are capable of including various factors and effects. According to Autant-Bernard and Hazir (2013, p. 2):

the capacity of ERGM to investigate the role of geography is threefold. First, it may be studied as the role of physical distance by means of a distance interaction function (Daraganova et al. 2012). Second, geography may be included as a node attribute. Third, geography can be considered as a spatial setting that imposes limits on tie dependence, hence on local configurations (Pattison and Robbins 2002).

To define the model in general terms, we assume that we have $n$ observational units $i=1,2, \ldots, n$, and for each ordered pair of units $(i, j)$ we record whether they are relationally tied or not, defining the binary variables

$$
X_{i j}=\left\{\begin{array}{cc}
1 & \text { if } i \text { has a tie to } j \\
0 & \text { otherwise }
\end{array}\right.
$$

Standard statistical models for binary data may be applied for modelling $X_{12}, X_{13}, \ldots, X_{n(n-1)}$ but it is clear that the cross-classification of $X_{i j}$ by the sender $i$ and the receiver $j$, is something that potentially induces dependencies and endogeneity in data. This is a phenomenon that has a long tradition of research in spatial statistics and geographical modelling (e.g. Cressie 1991). Spatially embedđed data often exhibit complicated dependencies through a spatial weighting matrix $\mathbf{W}=\left(W_{i j}\right)$ (Getis 2009) that can either represent contiguities (Cliff and Ord 1972), pairwise distances, or some other spatial functions (Oshan and Fotheringham 2018). If we consider unit-level outcomes $\mathbf{Y}=\left(Y_{i}\right)$, the adjacency matrix $\mathbf{X}=\left(X_{i j}:(j, j) \in V \times V\right)$, can be taken into account in analogous ways to how $\mathbf{W}$ is used in spatial analysis (Marsden and Friedkin 
1993; Leenders 2002; Koskinen and Stenberg 2012). Here we aim to model $\mathbf{X}$ itself, which would be analogous to modelling the weight matrix in geographical analysis. While ERGM is a form of gaussian Markov random field that is related to models in spatial statistics (Moller and Waagepetersen 2003; Rue and Held 2005), the neighborhood structure that induces dependence is not given by $\mathbf{X}$ itself (Koskinen 2018). In a seminal paper Frank and Strauss (1986) defined a dependence structure on $\mathbf{X}$ in terms of the node-labels. More specifically, they proposed the following Markov dependence structure:

$$
X_{i j} \perp X_{k \ell} \mid\left\{X_{u v}:(u, v) \in V^{(2)} \backslash\{(i, j),(k, \ell)\}\right\},(i, j) \cap(k, \ell)=\emptyset,
$$

where $V^{(2)}=V \times V$. In other words, two tie-variables are assumed to be conditionally independent given the rest of the variables if the two ties do not share a node. Using the Hammersley-Clifford theorem (Besag 1974), they derived a set of sufficient statistics for a network under this Markov assumption. These statistics have the form of interaction terms $\prod_{(i, j) \in A} X_{i j}$ in a log-linear model. Some interactions $A$ follow straightforwardly from the dependence assumption, like $X_{i j} X_{i k}$ which corresponds to a network out-2-star. Other interactions are more involved but turn out to directly correspond to network sub-graphs that had a long tradition of being investigated in network research, such as the transitive triple $X_{i j} X_{i k} X_{j k}$ (Holland and Leinhardt 1975). Drawing on realisation-dependence (Baddeley and Møller 1989), Pattison and Robins (2002) defined an extension of the Markov dependence assumptions that was subsequently elaborated for ERGM in the social circuit dependence model (Snijders et al. 2006). The social circuit dependence assumption allows tie-variables $X_{i j}$ and $X_{k \ell}$ to be conditionally dependent even if the ties do not share a node, i.e. $(i, j) \cap(k, \ell)=\emptyset$, provided that there are ties $x_{i k}=x_{j \ell}=1$ or $x_{j k}=x_{i \ell}=1$ that connect them. In other words, tie-variables may be conditionally dependent if they would complete a four-cycle. Snijders et al. (2006) define an alternating triangle statistic to capture this dependence (this was later elaborated for directed networks by Robins et al. 2009).

To apply ERGM requires making a homogeneity assumption in order to reduce the number of parameters. For example, the Markov model (Frank and Strauss 1986), implies a parameter $\theta_{M, i j}$ for each mutuality interaction term $X_{i j} X_{j i}$ for all $n(n-1) / 2$ pairs and the assumption that $\theta_{M, i j}=\theta_{M}$ for all $(i, j)$ is typically made (only recently have diagnostics for detecting departures from this homogeneity assumption been developed, see Koskinen et al. 2018). 
In addition to statistics that capture endogenous network-dependencies, incorporating fixed exogenous node-level and dyadic covariates is straightforward. A particularly important exogenous factor is the spatial embedding $s_{i}$ of the nodes $i=1,2, \ldots, n$. Daraganova et al. (2012) argued that seeing as both endogenous network dependencies as well as spatial embedding of nodes will potentially lead to clustering of ties in the network, both processes need to be accounted for in the ERGM. When there is a positive interaction effect for transitive closure $X_{i j} X_{i k} X_{j k}$, ties cluster in the sense that the conditional probability of $X_{i j}=1$ given $x_{i k}$ and $x_{j k}$ may be greater when $x_{i k}=x_{j k}=1$ than when $x_{i k}=x_{j k}=0$. With $f\left(s_{i}, s_{j}\right)$ some relevant function of nodes $i$ and $j$ 's position in space, we may find that the conditional probability of $X_{i j}=1$ differs for different values of $f\left(s_{i}, s_{j}\right)$. In particular, if $f\left(s_{i}, s_{j}\right)$ is distance, ties might cluster around nodes that are close. Defining $\mathbf{D}=\left(D_{i j}\right)$ as the matrix of pairwise distances between nodes, Daraganova (2009) demonstrated that inclusion of the statistic $X_{i j} \log \left(D_{i j}\right)$ was equivalent to assuming a distance interaction function under which tie-probability decreases as an attenuated power-law function of distance. Daraganova (2009) further discussed a number of additional ways in which to interact the spatial embedding of nodes with the network ties but little has been done in investigating the spatial embedding of network ties. Still using only distance, Koskinen and Lomi (2013) draw on the spatial literature and argue that the gravity model (Tinbergen 1962) can be adapted for binary ties and represented through the interactions $X_{i j} \log \left(M_{i}\right), X_{i j} \log \left(M_{j}\right)$, and $X_{i j} \log \left(D_{i j}\right)$, where $M_{i}$ is the 'mass' of node $i$. Combining gravity model elements with endogenous network factors may reveal ways in which spatial dependence confounds network dependencies and vice versa. ERGM offer the opportunity to elaborate this further by incorporating more advanced spatial effects than have been previously attempted. As noted in Daraganova (2009), more general interactions of functions of spatial position and network dependencies follow from Robins et al (2001). For example, interactions of triples and position $f\left(s_{i}, s_{j}, s_{k}\right) X_{i j} X_{i k} X_{j k}$. In particular, in the sequel we will consider $f_{B}\left(s_{i}, s_{j}\right)$ indicating whether $i$ and $j$ are separated by a border or not. A cross-border pair would correspond to $f_{B}\left(s_{i}, s_{j}\right)=1$; a pair in the same territory would correspond to $f_{B}\left(s_{i}, s_{j}\right)=0$; and a triple of nodes in three distinct territories would for example be given by $f_{B}\left(s_{i}, s_{j}\right) f_{B}\left(s_{i}, s_{k}\right) f_{B}\left(s_{j}, s_{k}\right)=$ 1.

This article is protected by copyright. All rights reserved 


\section{Empirical setting}

In the context of European integration and cross-border regionalization, a wide variety of public and private actors are involved in building cross-border regions (for an overview, see Perkmann 2003). This joint effort gives rise to a diffuse form of governance that encourages voluntary partnerships and is contingent on multilateral connections that do not necessarily conform to the national boundaries of the states concerned. The policy domain investigated in this paper concerns cross-border public transportation. This is a key domain since cross-border mobility is crucial for local and regional actors in fostering regional integration and competitiveness.

The selection of the empirical cases is based on two criteria. First, the cross-border regions under scrutiny must be representative of cross-border regionalism as it developed in Europe in recent decades. Second, the case studies must display similarities in the spatial parameters we study in accordance with a research design based on 'literal replication' where the cases are designed to corroborate each other (Yin 2014). In this way, we intend to provide groundwork for new analytical generalizations regarding the combined effects of spatial factors on policy networks. Based on these criteria, the two cross-border regions of Basel and Lille are chosen. In the case of Basel, cross-border relations have a long history, the Regio Basiliensis created in 1963 being one of the oldest cross-border cooperation initiatives in Europe. Currently, several cross-border cooperation structures and initiatives co-exist within the cross-border region and act in favor of planning and implementation of cross-border transportation infrastructure (Walther and Reitel 2013). In the case of Lille, public and private actors have been actively cooperating since the 1990s resulting in the creation of the Eurometropolis Lille-Kortrijk-Tournai (Durand and Nelles 2014).

The comparison of the effects of space on policy relations in the two regions is based on the existence of similarities in the two key independent variables of theoretical interest in this paper (see Figure 1). As far as the variable distance is concerned, the two cross-border regions exhibit a similar geographical structure, especially with regard to the location of the organizations involved in public transportation planning and governance (most actors are located within the main urban centers - Basel and Lille - while the maximum distance between them does not exceed $150 \mathrm{~km}$ ). Concerning the border setting, the two cases are crisscrossed by several territorial borders. The Basel cross-border region is located at a tripoint where Switzerland, France and Germany meet. Although Switzerland is not part of the European Union, bilateral 
agreements signed in the early 2000s and the integration of Switzerland into the Schengen area guarantee free movement of goods and people across Swiss borders. For its part, Lille is located at the French-Belgian border. This EU internal border between two founding member states shows a high level of socio-economic and institutional integration (Durand and Nelles 2014). On the Belgian side, the regional distinction between Wallonia and Flanders adds an additional boundary that is taken into consideration in this study due to its political relevance.

[Insert figure 1 here]

\section{Data and methods}

The presentation of the data and methodology is structured in four parts. First, we explain the approach followed to define the boundary of the policy networks targeted and identify the individual informants to be interviewed. The second and third sections present the dependent and independent variables. The last section is dedicated to our modeling strategy.

\section{Identification of actors}

Information on the public transportation policy domain under scrutiny in Lille and Basel was derived from face-to-face interviews conducted in the spring of 2011. The boundary definition of the policy networks combined a reputational analysis based on external experts and a nomination process through a name-generator of informants. During data collection we interviewed managers, CEOs, heads of office or senior administrators of the relevant policy domain who we can safely assume to possess a fair understanding of the political actions of their respective organization. In total, we interviewed 33 informants in Lille and 44 in Basel. The responses from the informants interviewed were aggregated at the level of organization based on their respective affiliation. This corresponds to 22 organizations in both cases. The response rates at the organization level is respectively $100 \%$ and $91.6 \%$.

[Insert table 1 here]

The distribution of organizations by nationality reflects the territorial setting prevailing in the cross-border regions of Lille and Basel (see Table 1 and Figure 1). In the case of Lille, there are more Belgian actors than French, despite the fact that the main city (Lille) is located in 
France. This is due to the presence of two regions (Flanders and Wallonia) within the crossborder region. In Basel, most organizations are located in the Cantons of Basel-City and BaselCountry as the main urban agglomeration. The French and German organizations are in the minority and located near Basel and in the Alsatian capital (Strasbourg). For both cases, around half of the organizations are local and regional authorities, which reflects the high institutionalization of cross-border cooperation in Europe. Thus, in the case of Lille, we find on the French side the region of Nord-Pas-de-Calais, the General Council of the North, the Lille metropolis and on the Belgian side, the regions of Flanders and Wallonia as well as several associations of municipalities (intercommunales). In the case of Basel, the Swiss cantons of Basel-City and Basel-Country are present as well as French and German neighboring border municipalities (St Louis and Lörrach) and the region of Alsace. With regard to the involvement of the central states, it is only in Lille's case where the Belgian federal state is present directly and the French state is represented through the regional Prefecture. Besides those public actors, a large variety of organizations participate in the public transportation networks, such as crossborder cooperation organizations, chamber and development agencies as well as railways firms (such as the French SNCF, the Belgian SNCB and the Swiss SBB) and various bus companies.

\section{Dependent variable}

The tie variables $\mathbf{X}=\left(X_{i j}\right)$ of interest in our study are the pairwise exchanges of information among organizations between 2009 and 2010. Actors were asked to report with whom they exchange information relative to cross-border public transportation. Information exchange includes all interactions through face-to-face contact, phone, email, social media or the circulation of documents to a specific person/officer within and between organizations. This does not include generally distributed emails or memos.

For the two cases, the data on information exchange show high levels of interaction (densities of 0.50 and 0.465$)$ and modest levels of reciprocity (0.459 and 0.387$)$. This level of density is associated with the empirical context (the salience of this policy domain to actors interviewed) and focuses on core actors within the respective policy networks.

\section{Independent variables}


Given the geographical concerns in our analysis of cross-border policy networks, the main independent variables of theoretical interest in this paper are the two spatial variables, which are treated as dyadic covariates.

The first variable is Distance, $\mathbf{D}=\left(D_{i j}\right)$. The spatial location of each organization was assessed by its street address and Euclidian distance was calculated from one address to another by using latitude and longitude coordinates. Table 2 summarizes the geographical data for the two networks and shows that both present a wide range of distances.

[Insert table 2 here]

Despite the common assumption in the literature that the probability of social interaction decreases with distance, the precise relationship between these two variables remains unclear (Scellato et al. 2011). Based on the findings presented by Butts (2003), as discussed above, we assume that the effect of distance marginally follows an attenuated power-law function $\operatorname{Pr}\left(X_{i j}=\right.$ $\left.1 \mid D_{i j}\right)=\left(1+\alpha D_{i j}^{\gamma}\right)^{-1}$, which in ERGM can be parameterized through the interaction term $\sum_{i=1}^{n} X_{i j} \log \left(D_{i j}\right)$ (Daraganova et al. 2012). Further, because the distance interaction function (DIF) is sensitive to very small distances (ibib.), tie variables for dyads with pairwise distances arbitrarily small were treated as fixed in the estimation. In the context of our empirical example, this relates to organizations that are located in adjacent buildings and that are therefore at very short distances.

The second spatial variable is Territorial borders. Given the existence of nested territorial levels (region, country) which imply the existence of different types of territorial boundaries (i.e., regional, national), this variable was not operationalized on the basis of an attribute of the actors (e.g., French, Swiss, Belgian, etc.) but through a binary matrix $\mathbf{T}=\left(T_{i j}\right)$ that indicates whether two organizations belong to the same territorial unit $\left(T_{i j}=1\right)$ or not $\left(T_{i j}=0\right)$ (or $T_{i j}=1-f_{B}\left(s_{i}, s_{j}\right)$ in terms of the earlier notation). Specifically, this amounts to defining whether they share 'domestic' ties or share 'cross-border' ties. For both cases, the first level of territoriality is the national level, namely, Belgium and France for Lille and Switzerland, France and Germany for Basel. However, the political structure of Belgium requires that the boundary between the two Belgian regions of Wallonia and Flanders is also taken into account. Finally, for both case studies, cross-border organizations were considered to be 'tri-national' (i.e., they share 
'domestic' ties with all other actors of the policy networks). In doing so, it has been possible to integrate borders at different territorial scales (i.e., regional, national and interregional).

In both cross-border regions, the cross-border cooperation is organized around formal structures. The co-affiliation of the organizations to these cooperation structures engenders the development of strong ties which are susceptible to impact the ways the exchange of information occurs. Therefore, the variable Cross-border cooperation, $\mathbf{C}=\left(C_{i j}\right)$, serves as a control for the co-affiliation of organizations to cross-border cooperation structures.

Given the heterogeneity of the studied policy networks, an attribute variable labelled Prominent actors was also included in the analysis in order to control for the effects of different types of actors. This binary variable was computed from the answers that survey respondents provided to the question: 'Considering cross-border public transportation, could you nominate the most prominent actors?' All those organizations nominated more than five times considered to be widely recognized as prominent actors $\left(Y_{i}=1\right)$, and others unimportant $\left(Y_{i}=0\right)$. In both cross-border regions, these are mainly local and regional public authorities as well as private transport companies.

\section{Analytical strategy}

To assess the effects of geographical space on policy network processes, ERGM were fitted to each case study ${ }^{\mathrm{i}}$.

In this research, the two spatial effects were treated as exogenous dyadic covariates. The structural effects that arise from self-organizing network and attribute-based processes were also considered, although no specific hypotheses were formulated because they were used primarily as controls for the examination of the spatial effects. To investigate the different dimensions of the distance effect that are explained by other factors, we fit three specifications, gradually adding other effects (i.e. structural, attributes and other contextual factors).

For controlling the structural effects, eight basic parameters were entered into the models. The rationale for the structural effects is here primarily to control for endogenous dependencies. Of the types of dependency assumptions that have been proposed in the literature (Pattison and Snijders 2013), the most straightforward one is the Markov dependence assumption (Frank and Strauss 1986). Markov models are typically unstable and difficult to fit and social circuit 
dependence models are generally recommended (Snijders et al. 2006). For very dense networks, Markov models may however fit appropriate data. ${ }^{\text {ii }}$

We include a selection of the simpler lower-order Markov configurations with the intention to capture endogenous in-degree and out-degree dependencies as well as clustering. The Arc effect is the baseline effect that reflects the propensity for tie formation. Whether ties are reciprocated or not is examined with the Reciprocity effect. The in-2-stars (In2Star) and in-3stars (In3Star) are star-like structures with two or three ingoing ties from the central node that are often described in terms of 'popularity'; essentially, these parameters help model the shape of the in-degree distribution. Similarly, out-2-stars (Out2Star) and out-3-stars (Out3Star) are out-star structures that represent activity-based configurations for modeling the out-degree distribution. Finally, Transitive-Triad and Cyclic-Triad reflect closure patterns within triads, either through transitivity or cyclic effects (see Lusher et al. 2013). In order to control for attribute-based processes, the variable Prominent actors was considered according to three parameters: the Sender effect reflecting activity, the Receiver effect reflecting popularity and Interaction reflecting homophily. The full model is given as

$$
\begin{aligned}
p(\mathbf{X} \mid \mathbf{D}, \mathbf{T}, \mathbf{C}, \mathbf{Y}, \boldsymbol{\theta}) \\
=\exp \left\{\boldsymbol{\theta}_{A}^{\top} \mathbf{z}_{A}(\mathbf{X})+\boldsymbol{\theta}_{Y}^{\top} \mathbf{z}_{Y}(\mathbf{X}, \boldsymbol{Y})+\boldsymbol{\theta}_{D}^{\top} \boldsymbol{Z}_{\boldsymbol{D}}(\mathbf{X}, \boldsymbol{D})+\boldsymbol{\theta}_{T}^{\top} \mathbf{z}_{T}(\mathbf{X}, \boldsymbol{T})+\boldsymbol{\theta}_{C}^{\top} \mathbf{Z}_{C}(\mathbf{X}, \boldsymbol{C})\right. \\
-\boldsymbol{\psi}(\boldsymbol{\theta})\}
\end{aligned}
$$

where

$$
\begin{gathered}
\boldsymbol{\theta}_{A}^{\top} \mathbf{z}_{\boldsymbol{A}}(\mathbf{X})=\theta_{1} \sum_{i \neq j} X_{i j}+\theta_{2} \sum_{i<j} X_{i j} X_{j i}+\theta_{3} \sum_{\substack{i \neq j, k \\
j<k}} X_{i j} X_{i k}+\theta_{4} \sum_{\substack{i \neq j, k \\
j<k}} X_{j i} X_{k i}+\theta_{5} \sum_{\substack{i \neq j, k, \ell \\
j<k<l}} X_{i j} X_{i k} X_{i \ell} \\
+\theta_{6} \sum_{\substack{i \neq j, k, \ell \\
j<k<l}} X_{j i} X_{k i} X_{\ell i}+\theta_{7} \sum_{\substack{(i, j, k) \in\left(\begin{array}{c}
V \\
3
\end{array}\right) \\
j<k}} X_{i j} X_{i k} X_{j k}+\theta_{8} \sum_{\substack{(i, j, k) \in\left(\begin{array}{c}
V \\
3
\end{array}\right) \\
X_{i j}}} X_{j k} X_{k i},
\end{gathered}
$$

are the endogenous network effects,

$$
\boldsymbol{\theta}_{Y}^{\top} \mathbf{Z}_{\boldsymbol{Y}}(\mathbf{X}, \boldsymbol{Y})=\theta_{9} \sum_{i \neq j} X_{i j} Y_{i}+\theta_{10} \sum_{i \neq j} X_{j i} Y_{i}+\theta_{11} \sum_{i \neq j} X_{i j} Y_{i} Y_{j}
$$

are the effects of prominent actors, 


$$
\boldsymbol{\theta}_{\boldsymbol{D}}^{\top} \mathbf{z}_{\boldsymbol{D}}(\mathbf{X}, \boldsymbol{D})=\theta_{12} \sum_{i \neq j} X_{i j} \log \left(D_{i j}\right)
$$

is the distance effect,

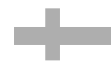

is the territoriality effect,

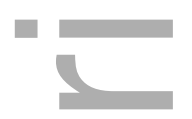

is the territoriality effect,

$$
\boldsymbol{\theta}_{T}^{\top} \mathbf{z}_{T}(\mathbf{X}, \boldsymbol{T})=\theta_{13} \sum_{i \neq j} X_{i j} T_{i j}
$$

$$
\boldsymbol{\theta}_{C}^{\top} \mathbf{z}_{C}(\mathbf{X}, \boldsymbol{C})=\theta_{14} \sum_{i \neq j} X_{i j} C_{i j}
$$

is the collaboration effect and $\boldsymbol{\psi}(\boldsymbol{\theta})$ is a normalizing constant.

The moderation effect among the spatial variables was examined according to the following method. In order to assess whether the effect of distance on information exchange varies according to territorial borders, the policy networks were split into two subsets, domestic ties, $\mathbf{X}_{D}=\left(X_{i j}: T_{i j}=1\right)$, and cross-border ties, $\mathbf{X}_{C B}=\left(X_{i j}: T_{i j}=0\right)$. We then modeled each of these subsets using ERGM conditional on the other subset. In other words, we analyzed domestic ties while treating cross-border ties as exogenous and vice-versa. ${ }^{\text {iii }}$

Comparing the parameter estimates of the models allowed us to detect specific effects. The moderation effect of territorial borders on distance is thus represented by the differences in the distance parameter between the models conditioned on cross-border ties and domestic ties, respectively. Care has to be taken to account for the conditioning when interpreting these models. Clearly, analyzing the subsets separately is only statistically appropriate when the ties of the subsets are independent of each other, something that they are clearly not. We interpret these models with this in mind, where the results explain the tie-formation of one node-set when these are considered embedded in the other node-set. We necessarily have to entertain the possibility that one of the conditional models is more appropriate ${ }^{\mathrm{iv}}$. This approach circumvents the need for exploring all possible interactions of $f_{B}$ and network statistics. As argued above, the effect on the DIF (i.e. whether the distance-decay on tie formation is affected by borders) was examined by comparing the predictive distributions $\mathbf{X}^{\text {rep }} \sim p\left(\mathbf{X} \mid \mathbf{D}, \mathbf{T}, \mathbf{C}, \mathbf{Y}, \widehat{\boldsymbol{\theta}}_{\mathrm{MLE}}\right)$ to observations $\mathbf{X}$.

\section{Results}

The presentation of our results is separated into two parts. First, we consider the overall effects of space on the two policy networks. Second, we focus on the moderation between different 
spatial effects. All the final models presented have converged and show an excellent fit to the data .

\section{General effects of space}

Table 3 presents the parameter estimates (and standard errors) for the general model applied to the Lille and Basel policy networks. For both contexts, the negative effect of distance (models A) is attenuated by successive addition of extra-dyadic effects (models B) and then the actor's attribute and other contextual effects (models $\mathrm{C}$ ). Whereas the effect of distance remains significant in Lille (albeit weakening), in Basel, once we control for endogenous structural effects distance is not significant anymore.

[Insert table 2 here]

For models B, the structural effects are standard for directed networks, with positive reciprocity and a tendency to local hierarchical structure (the combination of positive transitivity and negative cyclicity, the former being insignificant for Basel) (Lusher and Robins 2013). For models C, there appears to be no homophily among prominent actors in either network. Crossborder cooperation has a positive and significant effect for Lille, but not for Basel. Other conditions being equal, this result suggests that members of the cross-border cooperation structure in Lille tend to exchange more information with one another compared with among non-members. Finally, the significant negative effect of territorial borders for Lille and Basel shows the persistence of a barrier effect in terms of cross-border policy interactions.

In conclusion, the results obtained confirms the contingent effect of spatial distance on interactions. They also show how the distance effect is confounded by endogenous network dependencies. The persistence of a negative effect of territorial borders highlights that just because national borders have become more porous and cross-border cooperation occurs, does not imply that all barrier effects have disappeared. Next we investigate the moderation effect between territorial borders and distance.

\section{Interactions among spatial variables}


The question we tackle is whether distance works the same for ties that span borders and those that do not. Following the analytical strategy, two models are defined for each case study, one for domestic ties and another for cross-border ties (Table 4). The results for each case are interpreted as if the other domain were fixed and known.

\section{[Insert table 4 here]}

In both cases, the coefficients for distance in Table 4 are negative for domestic ties and positive for cross-border ties. While the distance effect is attenuated by inclusion of additional effects and not significant for Basel, the results indicate that distance affects collaboration within a territorial unit and across territorial units differently. These differences operate over and above the barrier effect reflected by the differences in densities (Arc in Table 4 and Territorial border in Table 3) and to investigate these further we look at the marginal effect of distance for the different types of ties using a goodness-of-fit procedure.

To define a marginal effect of distance we consider the empirical and simulated DIF. From Daraganova et al. (2012), we know that a negative coefficient for log distance in a dyadindependent ERGM implies a DIF that takes the form of an attenuated power-law. While the fit of the DIF to the data can be assessed for a dyad-independent model, the conditional DIF in a Markov model

$$
\widehat{\pi}(d)=\operatorname{Pr}\left(X_{i j}=1 \mid D_{i j}=d\right)=\sum_{\mathbf{X}} \sum_{i \neq j} x_{i j} 1\left\{D_{i j}=d\right\} p\left(\mathbf{X} \mid \mathbf{D}, \mathbf{T}, \mathbf{C}, \mathbf{Y}, \widehat{\boldsymbol{\theta}}_{\mathrm{MLE}}\right)
$$

is not available in an analytically tractable form. In order to validate and understand the effect of distance over and above the other covariate effects and endogenous dependencies, we rely on the predictive distributions implied by our fitted models. Specifically, we generate a GOF distribution by drawing replicate data from our fitted models $p\left(\mathbf{X}_{D} \mid \mathbf{X}_{C B}, \mathbf{D}, \mathbf{T}, \mathbf{C}, \mathbf{Y}, \widehat{\boldsymbol{\theta}}_{\mathrm{MLE}}\right)$ and $p\left(\mathbf{X}_{C B} \mid \mathbf{X}_{D}, \mathbf{D}, \mathbf{T}, \mathbf{C}, \mathbf{Y}, \widehat{\boldsymbol{\theta}}_{\mathrm{MLE}}\right)$ (Hunter, Goodreau, and Handcock 2008) and compare the empirical DIFs of the replicate data to the observed DIFs. For the empirical DIFs, we then fit a LOESS curve of tie probability to distance. We produce GOF distributions for each pair of models (i.e. cross-border and domestic ties) and for both case studies. Figures 2 and 3 illustrate the Lille and Basel networks, respectively. For each figure, the first two graphs represent the entire network 
(all ties) under the dyad-independent models A (graph a) and the full in-homogenous Markov models $\mathrm{C}$ (graph b) of Table 3. The following two graphs correspond to cross-border ties (graph c) and domestic ties (graph d) (with the other fixed) as presented in models G and E of Table 4. ${ }^{\text {vi }}$

[Insert figure 2 here]

[Insert figure 3 here]

For both Lille and Basel the empirical DIF and predicted marginal DIF follow the same patterns in Figures 1 and 2. For all ties considered jointly (graph b corresponding to the unconditional Models $\mathrm{C}$ in Table 3), tie-probability decreases with distance. The GOF plots show that tie-probability decreases with distance for domestic ties (graph d), whereas it increases for cross-border ties (graph c). The gap in tie-frequency between domestic and cross-border ties at short distances becomes narrower at larger distances, implying that the barrier effect tends to decrease with distance and virtually disappears at large distances as the two curves meet. Hence, we note the absence of a cumulative barrier effect between distance and territorial borders. There are bumps and kinks in both the empirical DIFs and the predicted DIFs, representing spatial clustering of organizations, network clustering, and dependence on prominent actors. The GOF for the dyad-independent models (graph a) entirely lacks these bumps and kinks as it is entirely generated by an attenuated power-law (apart from the reciprocity effect). The DIF can be summarized as being affected by borders in two ways. Firstly, the fact that cross-border ties are less frequent and organizations on different sides of the border tend to be further apart inflates the effect of distance marginally. Secondly, in this policy area, the fact that tie-probability increases with distance for cross-border ties may attenuate the effect of distance marginally. The positive effect of distance on cross-border ties in this policy area is explained by the presence of prominent actors such as central or federal governmental organizations and national railway companies, which are located far away from the border and with whom municipalities, crossborder cooperation structures and regional authorities need to exchange information whatever the distance. Thus, in the case of Lille, the organizations located in the city of Lille have many links with organizations located in Brussels (federal capital of Belgium) and, to a lesser extent, in Namur (capital of the Walloon region), despite the significant distance separating these cities 
(see Figure 1). In the case of Basel, we find a similar configuration, with many exchanges of information between the Swiss organizations located in Basel-City and those located in Strasbourg, capital of the Alsace region in France.

In summary, Figures 2 and 3 indicate a good fit of the implied DIF net of any other effects and, while power to detect these effects appear to be smaller for Basel, the marginal effect of borders on distance appear to follow similar principles. In combination with the good fit of the standard GOF statistics of our fitted models, therefore, we have adequately accounted for not only the endogenous dependencies (via the Markov model), but also the spatial effects.

\section{Conclusions}

We have advocated in this paper for a combination of geographical and relational approaches in the analysis of the spatial dimension of social networks, whether at the level of individuals or organizations. On the one hand, geographers have long shown the importance of taking into account geographical arrangements beyond just the aspects of spatial distance. On the other hand, SNA has developed approaches and tools to address some of the methodological challenges that arise from considering the impact of geographical factors in the formation of social networks. In particular, we have highlighted the interest that ERGM may have for geographers who wish to distinguish spatial determinants from the interaction (i.e., attribute of localization, distance) from social determinants or endogenous network dependencies. Hence, the ability of ERGM to control for tie dependence appears useful for a better treatment of networks effects and to demarcate the role of geography more properly (Autant-Bernard and Hazir 2012).

In order to ground this claim in an empirical approach, we have scrutinized the ways spatial distance between organizations and the presence of territorial borders influence the structure of policy networks and the exchange of information. In the first step, the two spatial effects were modeled jointly with structural effects, actor attributes and other contextual effects as control variables using ERGM. For both public transportation policy networks under scrutiny, the effects of distance and borders were shown to be negative, although the effect of distance appeared to be more stable in Lille than in Basel. This result suggests that net of any distance effect, the territorial borders between France and Belgium as well as those between Switzerland, France and Germany do serve as barriers to policy interactions. 
In the second step, this paper also investigated the moderation effect among the spatial factors studied herein. We analyzed how distance affects information exchange by territoriality (i.e. domestic vs. cross-border ties). By making use of simulated predictive data derived from the model specification, we investigated the marginal distribution of tie probability as a function of distance for both domestic and cross-border relations, net of endogenous effects. For crossborder ties, instead of increasing with distance, however, the barrier effect seems to be strongest at short distances and weakens as distance grows. This was partly confirmed through the estimated model parameters. For both policy networks studied, these findings thus suggest that local actors tend to neglect their neighboring counterparts in favor of foreign actors located some distance from the border, especially ministries and other key players located in capital cities (at the regional or national level). Three reasons why some actors engage in long-distance ties that bridge what Bell and Zaheer (2007) have labelled 'geographical holes' can be advanced here. To coordinate public transportation policies in a cross-border setting, local actors may have to bridge distance in order to access strategic information they do not possess and is likely concentrated in remote decision centers. Secondly, local actors who are often marginalized in their home country because of their location on the margins of the national territory may also engage in cooperation relationships with prominent foreign actors for the purposes of symbolic and political recognition from their governing authorities (they become 'international' actors with paradiplomatic activities). Finally, since in Europe, cross-border cooperation is heavily funded by the European Commission through its INTERREG program, bringing distance and borders to reach out to important stakeholders might also be motivated by financial incentives.

Ultimately, as there is widespread acceptance that geography matters in the analysis of social interactions, this article has highlighted the usefulness of considering different aspects of geographical space. The consistency of results across the cases of Basel and Lille suggests that these mechanisms are not case-specific but may be generalized across similar contexts. While acknowledging that political ecosystems are inherently sui generis, we might expect to find similar patterns for other cross-border regions where functional reasons drive cross-border cooperation and policy interactions. This could also be relevant to regional borders and borders between states within a federation. We believe that the exploration of how multifaceted border effects - among other spatial factors - impact social relationships offers a promising avenue to future research.

This article is protected by copyright. All rights reserved 


\section{References}

Adams, J., K. Faust, and G.S. Lovasi. (2012). "Capturing context: Integrating spatial and social network analyses." Social Networks 34(1), 1-5.

Anderson, J.E., and E. Van Wincoop. (2003). Gravity with gravitas: a solution to the border puzzle. American Economic Review 93(1), 170-92.

Autant-Bernard, C., and C.S. Hazir (2013). "Network Formation and Geography: Modelling Approaches, Underlying Conceptions, Recent and Promising Extensions." In The Geography of Networks and R\&D Collaborations, 15-28, edited by T. Scherngell. Cham, $\mathrm{CH}$ : Springer International Publishing.

Baybeck, B., and R. Huckfeldt. (2002). "Urban contexts, spatially dispersed networks, and the diffusion of political information." Political Geography 21(2), 195-220.

Baddeley, A., and J. Møller. (1989) "Nearest-neighbour markov point processes and random sets.” International Statistical Review/Revue Internationale de Statistique 57(2), 89-121.

Bell, G.G., and A. Zaheer. (2007). “Geography, Networks, and Knowledge Flow.” Organization Science $18(6), 955-72$.

Besag, J. (1974). "Spatial interaction and the statistical analysis of lattice systems." Journal of the Royal Statistical Society, Series B 36, 192-225.

Boschma, R. (2005). "Proximity and Innovation: A Critical Assessment." Regional Studies 39(1), 61-74.

Broekel, T., P.A. Balland, M. Burger, and F. van Oort. (2014). "Modeling knowledge networks in economic geography: a discussion of four methods." The Annals of Regional Science 53(2), 423-52.

Broekel, T., and M. Hartog. (2013). "Explaining the Structure of Inter-Organizational Networks using Exponential Random Graph Models.” Industry and Innovation 20(3), 277-95.

Brueckner, J. K., and O. Smirnov. (2007). "Workings of the Melting Pot: Social Networks and the Evolution of Population Attributes.” Journal of Regional Science 47(2), 209-28.

Burger, M., F. Van Oort, and G.J. Linders. (2009). "On the specification of the gravity model of trade: Zeros, excess zeros and zero-inflated estimation.” Spatial Economic Analysis 4, 16790 .

This article is protected by copyright. All rights reserved 
Butts, C.T. (2003). "Predictability of large-scale spatially embedded networks." In Dynamic Social Network Modeling and Analysis, 313-23, edited by C. T. Butts, R. Breiger, K. Carley, P. Pattison. Washington, D.C.: National Academies Press.

Cassi, L., and A. Plunket. (2013). "Research Collaboration in Co-inventor Networks: Combining Closure, Bridging and Proximities.” Regional Studies 49(6), 1-19.

Cliff, A., and K. Ord. (1972). "Testing for spatial autocorrelation among regression residuals." Geographical analysis, 4(3), 267-84.

Cressie, N.A.C. (1991). Statistics for Spatial Data. Hoboken (NJ), Wiley.

Daraganova, G. (2009). Statistical models for social networks and network-mediated social influence processes: Theory and Applications. University of Melbourne, unpublished PhD thesis.

Daraganova, G., P. Pattison, J. Koskinen, B. Mitchell, A. Bill, M. Watts, and S. Baum. (2012). "Networks and geography: Modelling community network structures as the outcome of both spatial and network processes.” Social Networks 34(1), 6-17.

Durand, F., and J. Nelles. (2014). "Binding Cross-Border Regions: an Analysis of Cross-Border Governance in Lille-Kortrijk-Tournai Eurometropolis." Tijdschrift voor economische en sociale geografie 105, 573-90.

Engel, C., and J.H. Rogers. (1996). "How wide is the border?" American Economic Review $86(5), 1112-25$.

Festinger, L., S. Schachter, and K. Back. (1950). The spatial ecology of group formation. Palo Alto: Stanford University Press.

Fotheringham, A.S., and M.E. Reilly. (1989). Spatial Interaction Models; Formulations and Applications. Dordrecht: Kluwer Academic Publishers.

Frank, O., and D. Strauss. (1986). "Markov Graphs." Journal of the American Statistical Association 81(395), 832-42.

Getis, A. (2009). “Spatial weights matrices.” Geographical Analysis 41(4), 404-10.

Glückler, J. (2013). "Knowledge, networks and space: connectivity and the problem of noninteractive learning." Regional Studies 47(6), 880-94.

Glückler, J., E. Lazega, and I. Hammer. (2017). "Exploring the interaction of space and networks in the creation of knowledge: An introduction." In Knowledge and networks, Knowledge and 
Space, Vol. 11, 1-21, edited by J. Glückler, E. Lazega, I. Hammer. Cham, CH: Springer International Publishing.

Grabher, G. (2006). "Trading routes, bypasses, and risky intersections: mapping the travels of networks' between economic sociology and economic geography." Progress in Human Geography 30(2), 163-89.

Haggett, P., and R.J. Chorley. (1969). Network analysis in geography. London: Hodder \& Stoughton Educational.

Helliwell, J.F. (1998). How Much Do National Borders Matter? Washington: Brookings Institution Press.

Hipp, J.R., and A. J. Perrin. (2009). "The Simultaneous Effect of Social Distance and Physical Distance on the Formation of Neighborhood Ties." City \& Community 8(1), 5-25.

Holland, P.W., and S. Leinhardt. (1975) "Local structure in social networks." In Sociological Methodology, edited by D. Heise. San Francisco: Jossey-Bass.

Hunter, D.R., S.M. Goodreau, and M.S. Handcock. (2008). "Goodness of fit of social network models." Journal of the American Statistical Association 103(481), 248-58.

Koskinen, J. (in press). Exponential Random Graph Models, Wiley StatsRef: Statistics Reference Online. DOI: $10.1002 / 9781118445112$. stat08136.

Koskinen, J., and A. Lomi. (2013). "The local structure of globalization.” Journal of statistical physics 151(3-4), 523-48.

Koskinen, J., and S.A. Stenberg. (2012). "Bayesian analysis of multilevel probit models for data with friendship dependencies." Journal of Educational and Behavioural Statistics 37, $203-$ 30.

Koskinen, J., P. Wang, G. Robins, and P. Pattison. (2018). “Outliers and Influential Observations in Exponential Random Graph Models.” Psychometrika. Published online 18 September 2018. DOI: $10.1007 / \mathrm{s} 11336-018-9635-8$.

Leenders, R.T.A.J. (2002). "Modeling social influence through network autocorrelation: Constructing the weight matrix." Social Networks 24, 21-47.

LeSage, J.P., and Pace, R.K. (2008). "Spatial econometric modeling of origin-destination flows." Journal of Regional Science 48(5), 941-67.

Lomi, A., and F. Pallotti. (2012). "Relational collaboration among spatial multipoint competitors." Social Networks 34(1), 101-11.

This article is protected by copyright. All rights reserved 
Lusher, D., J. Koskinen, and G. Robins. (2013). Exponential Random Graph Models for Social Networks. Cambridge, UK: Cambridge University Press.

Lusher, D., and G. Robins. (2013). "Formation of social network structure.” In Exponential Random Graph Models for Social Networks, 16-28, edited by D. Lusher, J. Koskinen, G. Robins. Cambridge, UK: Cambridge University Press.

Marsden, P., and N. Friedkin. (1993). "Network studies of social-influence." Sociological Methods \& Research 22, 127-51.

Mok, D., B. Wellman, and J. Carrasco. (2010). "Does distance matter in the age of the Internet?" Urban Studies 47(13), 2747-83.

Moller, J., and R.P. Waagepetersen. (2003). Statistical Inference and Simulation for Spatial Point Processes. New York: Chapman and Hall/CRC.

Nijkamp, P., P. Rietveld, and I. Salomon. (1990). "Barriers in spatial interactions and communications.” The Annals of Regional Science, 24(4), 237-52.

Oshan, T.M., and A.S. Fotheringham. (2018). "A Comparison of Spatially Varying Regression Coefficient Estimates Using Geographically Weighted and Spatial-Filter-Based Techniques." Geographical Analysis 50(1), 53-75.

Pattison, P., and T.A.B Snijders. (2013). "Modeling Social Networks: Next Steps." In Exponential Random Graph Models for Social Networks: Theory, Methods, and Applications, 287-301, edited by D. Lusher, J. Koskinen, and G. Robins. Cambridge, UK: Cambridge University Press.

Pattison, P., and G. Robins. (2002). "Neighborhood-based models for social networks." Sociological Methodology 32(1), 301-37.

Perkmann, M. (2003). “Cross-border Regions in Europe. Significance and Drivers of Regional Cross-border Co-operation." European Urban and regional studies 10(2), 153-71.

Preciado, P., T.A.B. Snijders, W. J. Burk, H. Stattin, and M. Kerr. (2012). "Does proximity matter? Distance dependence of adolescent friendships." Social Networks 34(1), 18-31.

Radil, S.M., C. Flint, and G.E. Tita. (2010). "Spatializing Social Networks: Using Social Network Analysis to Investigate Geographies of Gang Rivalry, Territoriality, and Violence in Los Angeles.” Annals of the Association of American Geographers 100(2), 307-26.

Rietveld, P. (2012). "Barrier effects of borders: implications for border-crossing infrastructures." European Journal of Transport and Infrastructure Research 12(2), 150-66.

This article is protected by copyright. All rights reserved 
Robins, G., P. Elliott, and P. Pattison. (2001). "Network models for social selection processes." Social networks 23, 1-30.

Robins, G., P. Pattison, and P. Wang. (2009). "Closure, connectivity and degree distributions: Exponential random graph $\left(\mathrm{p}^{*}\right)$ models for directed social networks." Social Networks 31, 105-17.

Rue, H., and L. Held. (2005). Gaussian Markov random fields: theory and applications. New York: Chapman \& Hall/CRC.

Sailer, K., and I. McCulloh. (2012). "Social networks and spatial configuration. How office layouts drive social interaction." Social Networks 34(1), 47-58.

Scellato, S., A. Noulas, R. Lambiotte, and C. Mascolo. (2011). "Socio-spatial properties of online location-based social networks.” Proceedings of ICWSM 11, 329-36.

Snijders, T.A.B., P.E. Pattison, G.L. Robins, and M. S. Handcock. (2006). "New specifications for exponential random graph models." Sociological Methodology, 36, 99-153.

Sohn, C. (2014). "Modelling Cross-Border Integration: The Role of Borders as a Resource." Geopolitics 19(3), 587-608.

Sohn, C., and J. Licheron. (2018). "The multiple effects of borders on metropolitan functions in Europe." Regional Studies 52(11), 1512-24.

Ter Wal, A., and R. Boschma. (2009). "Applying social network analysis in economic geography: framing some key analytic issues.” Annals of Regional Science 43(3), 739-56.

Tinbergen, J. (1962). Shaping the world economy: Suggestions for an international economic policy. New York: Twentieth Century Fund.

Tobler, W.R. (1970). "A Computer Movie Simulating Urban Growth in the Detroit Region." Economic Geography 46(sup1), 234-40.

Van Geenhuizen, M.S., and R. Ratti. (Eds.). (2001). Gaining Advantage from Open Borders: An active space approach to regional development. Aldershot: Ashgate.

Vinciguerra, S., K. Frenken, and M. Valente. (2010). "The Geography of Internet Infrastructure: An Evolutionary Simulation Approach Based on Preferential Attachment." Urban Studies 47(9), 1969-84.

Walther, O., and B. Reitel. (2013). "Cross-border Policy Networks in the Basel Region: The Effect of National Borders and Brokerage Roles.” Space and Polity 17(2), 217-36.

Wang, P., G. Robins, and P. Pattison. (2009). PNet. Melbourne: University of Melbourne. 
Whittington, K.B., J. Owen-Smith, and W.W. Powell. (2009). Networks, Propinquity, and Innovation in Knowledge-intensive Industries. Administrative Science Quarterly 54(1), 90122.

Yin, R.K. (2014) Case study research: Design and methods (5th edition). Thousand Oaks, CA: Sage.

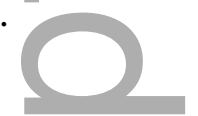

Table 1. Description of Organizations

\begin{tabular}{lcc}
\hline & Lille & Basel \\
\hline Number of organizations interviewed & 22 & 22 \\
Distribution by nationality & 8 & 6 \\
French organizations & 12 & - \\
Belgian organizations & - & 10 \\
Swiss organizations & - & 4 \\
German organizations & 2 & 2 \\
Cross-border organizations & & 6 \\
Distribution by type of organization & 5 & 5 \\
Local authorities & 5 & 0 \\
Regional authorities & 2 & 2 \\
Central states (ministries) & 2 & 1 \\
Cross-border organizations & 2 & 0 \\
Chambers of commerce & 1 & 7 \\
Development agencies & 5 & 1 \\
Firms & 0 & \\
Others & & \\
\hline
\end{tabular}


Table 2. Tie Distances for the two Policy Networks

\begin{tabular}{lrc}
\hline & Lille & Basel \\
\hline Mean $(\mathrm{km})$ & 47.5 & 39.2 \\
S.D. & 40.3 & 46.6 \\
Min $(\mathrm{km})$ & 0.3 & 0.01 \\
Max $(\mathrm{km})$ & 143.0 & 148.9 \\
\hline
\end{tabular}

Table 3. Parameter Estimates for the Lille and Basel Models

\begin{tabular}{|c|c|c|c|c|c|c|}
\hline \multirow{2}{*}{$\begin{array}{l}\text { Parameter } \\
\text { Structural effects }\end{array}$} & \multicolumn{3}{|c|}{$\begin{array}{c}\text { Lille } \\
\text { Estimates (SEs) }\end{array}$} & \multicolumn{3}{|c|}{$\begin{array}{c}\text { Basel } \\
\text { Estimates (SEs) }\end{array}$} \\
\hline & Model A & Model B & Model C & Model A & Model B & Model C \\
\hline Arc & $1.521 *(0.703)$ & $-0.337 \quad(1.107)$ & $0.360 \quad(1.232)$ & $0.756 \quad(0.587)$ & $-2.596^{*}(0.830)$ & $-3.91 *(1.169)$ \\
\hline Reciprocity & $1.069 *(0.292)$ & $1.033 *(0.350)$ & $0.681 \quad(0.347)$ & $0.699 * \quad(0.271)$ & $1.413 *(0.464)$ & $1.018^{*}(0.488)$ \\
\hline In2Star & & $0.023 \quad(0.116)$ & $-0.113 \quad(0.148)$ & & $0.296 *(0.075)$ & $0.321 *(0.092)$ \\
\hline Out2Star & & $0.0002(0.120)$ & $-0.101 \quad(0.139)$ & & $-0.034 \quad(0.154)$ & $0.121 \quad(0.224)$ \\
\hline In3Star & & $-0.012 \quad(0.011)$ & $-0.002 \quad(0.013)$ & & $-0.011 \quad(0.007)$ & $-0.012(0.007)$ \\
\hline Out3Star & & $-0.01 \quad(0.011)$ & $0.001 \quad(0.012)$ & & $0.001 \quad(0.018)$ & $-0.01 \quad(0.027)$ \\
\hline Transitive-T & & $0.210 *(0.044)$ & $0.216^{*}(0.051)$ & & $0.057 \quad(0.045)$ & $0.041 \quad(0.050)$ \\
\hline Cyclic-Triad & & $-0.269^{*}(0.054)$ & $-0.263 *(0.064)$ & & $-0.164 *(0.072)$ & $-0.171 *(0.077)$ \\
\hline Actor attribute effects & & & & & & \\
\hline Prominent a & & & $0.536 \quad(0.299)$ & & & $0.807 *(0.352)$ \\
\hline Sender & & & & & & \\
\hline Prominent actors & & & $1.063 *(0.37)$ & & & $0.346(0.249)$ \\
\hline Receiver & & & & & & ) \\
\hline Prominent & & & $-0.517 \quad(0.428)$ & & & $0.342(0.542)$ \\
\hline & & & & & & \\
\hline Other contextual effect & & & & & & \\
\hline Cross-borde & & & $0.327 *(0.164)$ & & & $-0164(0210)$ \\
\hline & & & & & & \\
\hline Spatial effects & & & & & & \\
\hline Distance & $-0.198^{*}(0.064)$ & $-0.121^{*}(0.053)$ & $-0.110 *(0.055)$ & $-0.126^{*}(0.057)$ & $-0.036(0.034)$ & $0.051 \quad(0.051)$ \\
\hline Territorial border & & & $-0.499 *(0.193)$ & & & $-1.27 *(0.278)$ \\
\hline
\end{tabular}

* Significant effect 
Table 4. Parameter Estimates for the Lille and Basel Models (Domestic vs. Cross-border Ties)

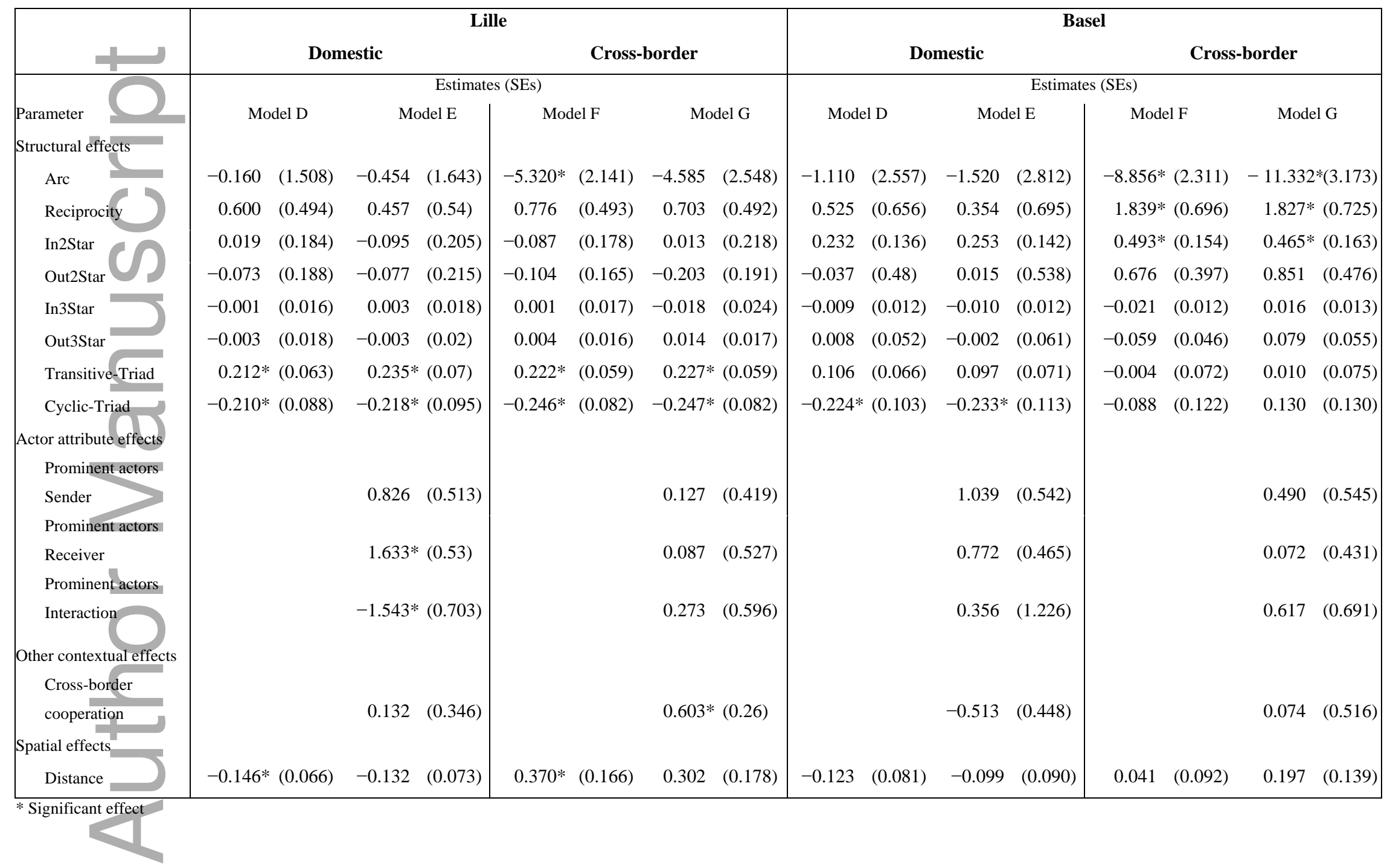

This article is protected by copyright. All rights reserved 


\section{Notes}

\footnotetext{
${ }^{\mathrm{i}}$ The ERGM modeling was performed in MPNet version 1.04 (Wang, Robins, and Pattison 2009).

${ }^{\text {ii }}$ Social-circuit type configurations were in this case difficult to fit to data and we are grateful to Peng Wang for the suggestion of using Markov models

iii In practice, this is performed in MPNet using 'structural zeros': a zero for a tie variable indicates that it should be considered to be fixed, whereas a one indicates that it should be modeled. The conditional models $p\left(\mathbf{X}_{D} \mid \mathbf{X}_{C B}, \mathbf{D}, \mathbf{T}, \mathbf{C}, \mathbf{Y}, \boldsymbol{\theta}\right)$ and $p\left(\mathbf{X}_{C D} \mid \mathbf{X}_{D}, \mathbf{D}, \mathbf{T}, \mathbf{C}, \mathbf{Y}, \boldsymbol{\theta}\right)$ have the same statistics as $p(\mathbf{X} \mid \mathbf{D}, \mathbf{T}, \mathbf{C}, \mathbf{Y}, \boldsymbol{\theta})$, for example $\boldsymbol{\theta}_{A}^{\top} \mathbf{z}_{A}\left(\mathbf{X}_{D} ; \mathbf{X}_{C B}\right)=\boldsymbol{\theta}_{A}^{\dagger} \mathbf{z}_{A}(\mathbf{X})$, if $\left(\mathbf{X}_{D}, \mathbf{X}_{C B}\right)$ is the partitioned form of $\mathbf{X}$ with the exception of $\mathbf{z}_{\boldsymbol{T}}(\mathbf{X}, \boldsymbol{T})$ which is not estimable.

iv We also fit interactions by using two separate distance matrices as dyadic covariates in the same model. The results, consistent with the present analyses but with a poor fit, are available from the authors on request.

${ }^{\mathrm{v}}$ Following the approach taken by Lusher, Koskinen and Robins (2013), the GOF $t$-ratios for the fitted statistics are all smaller than 0.1 in absolute terms. Moreover, all auxiliary statistics (available in MPNet) have GOF statistics smaller than 2 in absolute value, indicating a good fit (with the only exception being A2P-T, which was -2.1 in one of the models); The adequate fit thus includes for example the mixed 2-star statistic, meaning that the fitted model is sufficient for explaining the correlation of in- and out-degrees. In general, the entire triad census is well explained by the fitted models. The full GOF parameters may be obtained from the authors upon request.

${ }^{v i}$ The observed tie values are also included in the figures for reference (as indicated by circles); at the given distances, the circle is at zero or one on the vertical axes according to whether the tie is absent or not, respectively.
}

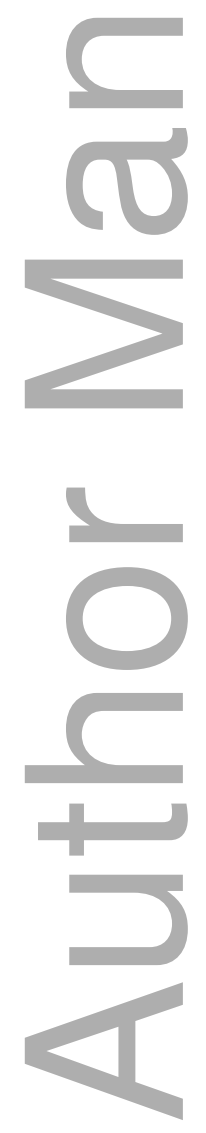




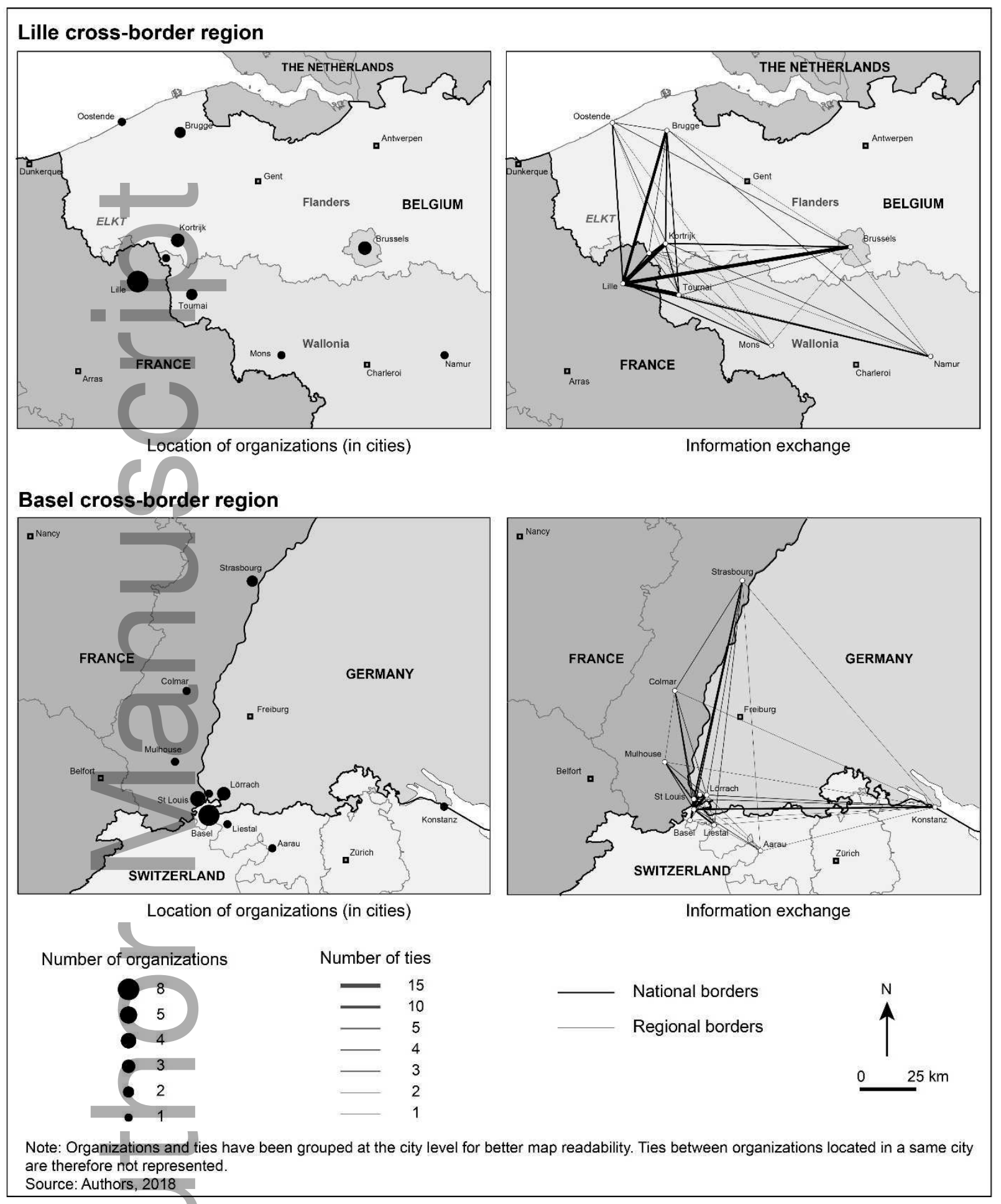

Figure 1. Location of organizations and spatial distribution of ties in Lille and Basel crossborder regions 
(a)
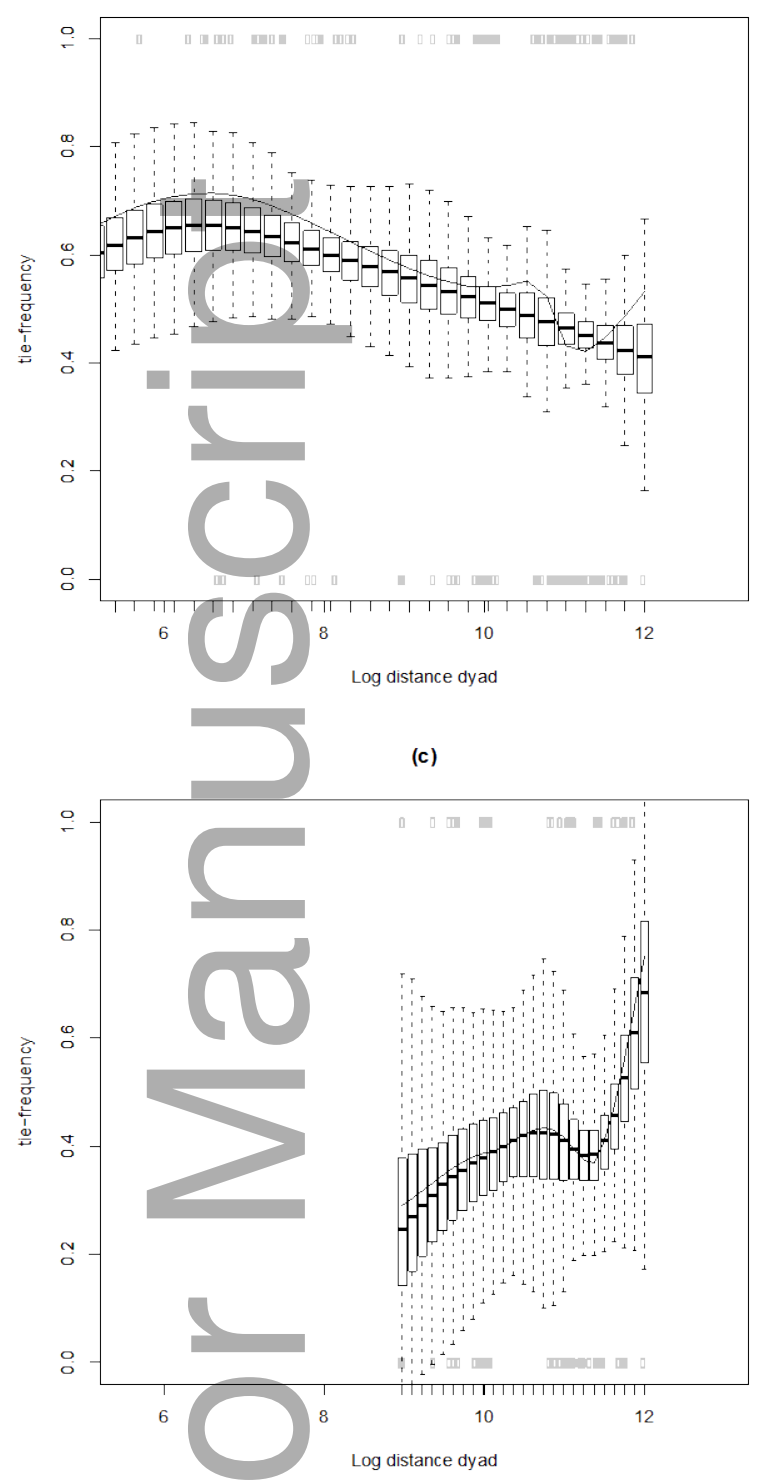

(b)

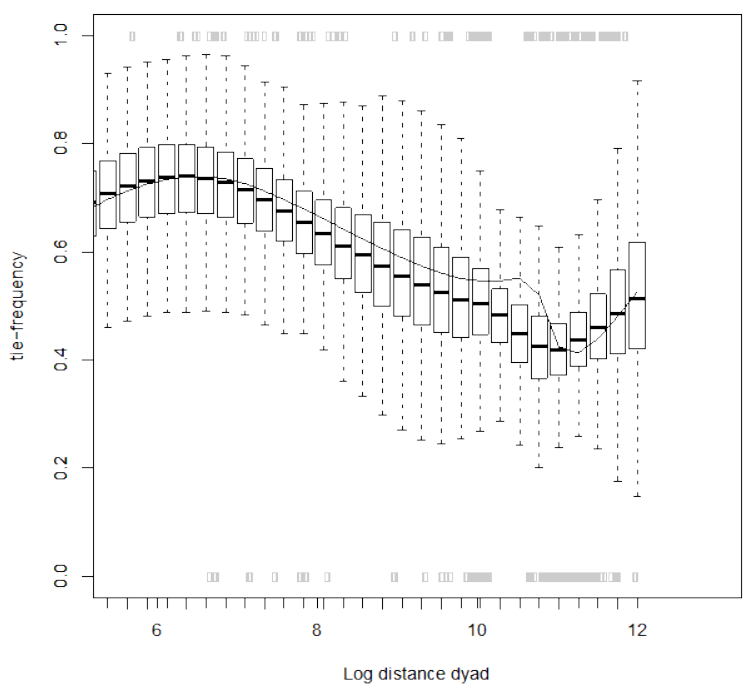

(d)

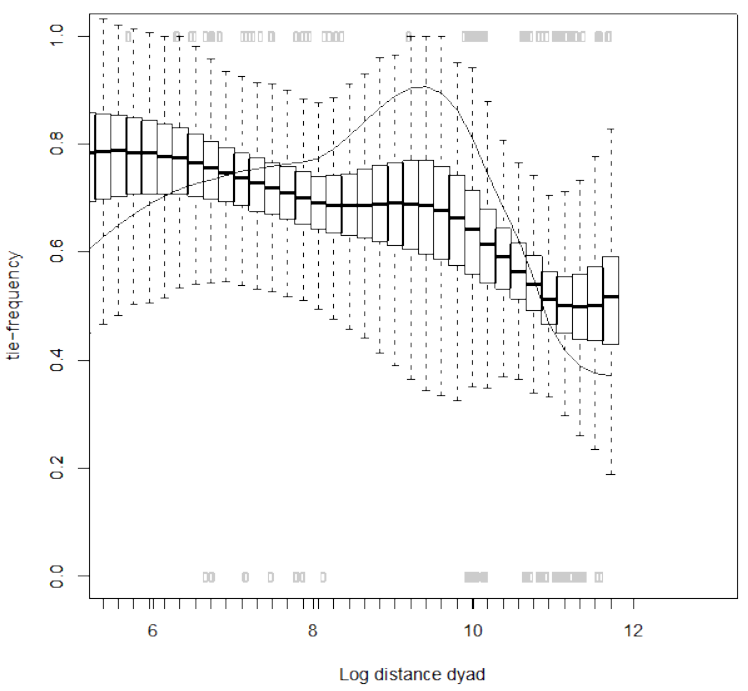

Figure 2. GOF for tie frequency according to distance. Empirical DIF LOESS curves for observed and predicted data for Lille. Dyad-independent model A (graph a) and model C (graph b) of Table 3, conditional model $\mathrm{G}$ for cross-border ties (graph c) and model $\mathrm{E}$ for domestic ties (graph d) of Table 4.

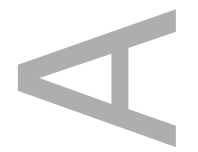


(a)
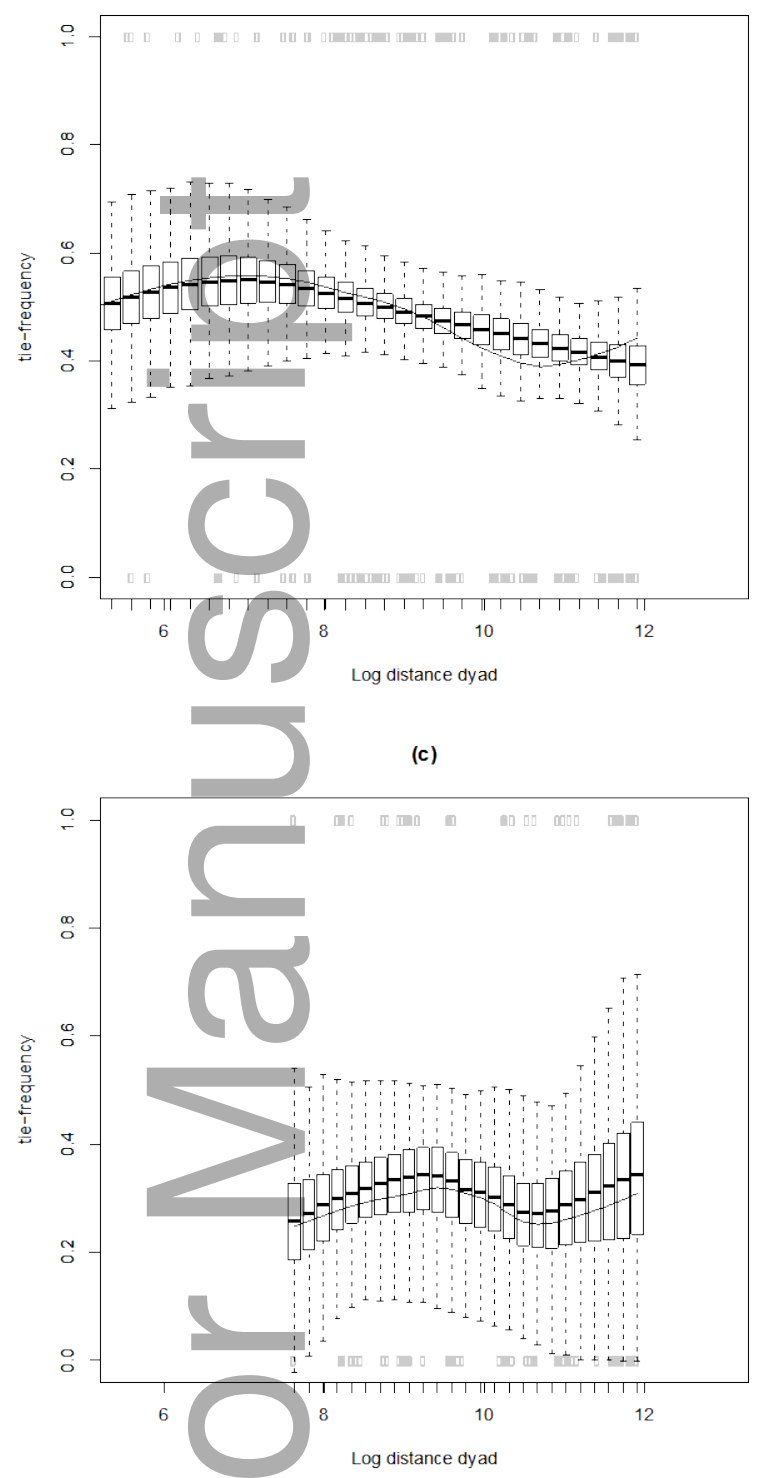

(b)

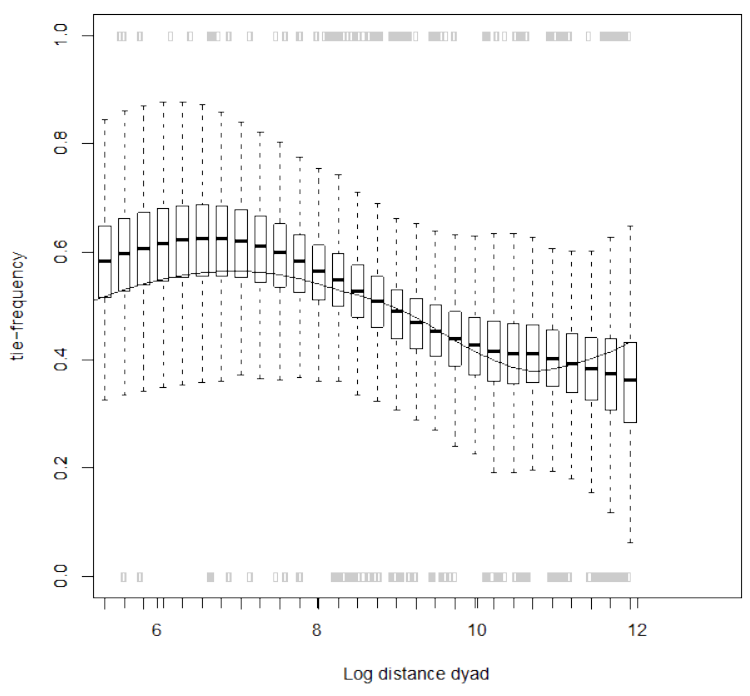

(d)

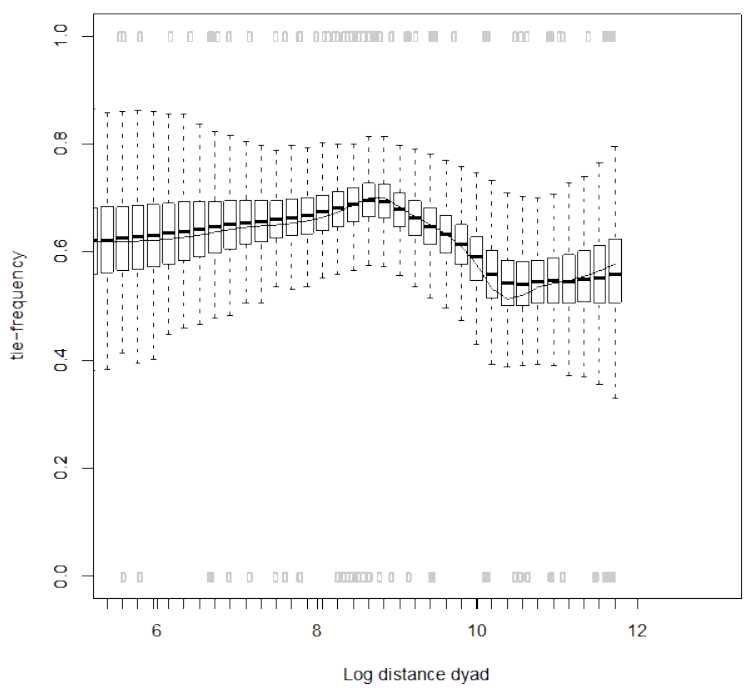

Figure 3. GOF for tie frequency according to distance. Empirical DIF LOESS curves for observed and predicted data for Basel. Dyad-independent model A (graph a) and model C (graph b) of Table 3, conditional model $\mathrm{G}$ for cross-border ties (graph c) and model $\mathrm{E}$ for domestic ties (graph d) of Table 4.

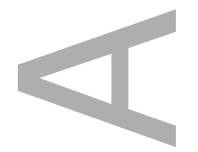




\section{University Library}

\section{- M M N E R VA A gateway to Melbourne's research publications}

Minerva Access is the Institutional Repository of The University of Melbourne

Author/s:

Sohn, C;Christopoulos, D;Koskinen, J

Title:

Borders Moderating Distance: A Social Network Analysis of Spatial Effects on Policy Interaction

Date:

2019-07-23

Citation:

Sohn, C., Christopoulos, D. \& Koskinen, J. (2019). Borders Moderating Distance: A Social Network Analysis of Spatial Effects on Policy Interaction. GEOGRAPHICAL ANALYSIS, 52 (3), pp.428-451. https://doi.org/10.1111/gean.12218.

Persistent Link:

http://hdl.handle.net/11343/286900 